\title{
POLÍTICAS PÚBLICAS E EDUCAÇÃO: O EQUILÍBRIO ENTRE A DISCRICIONARIEDADE E A VINCULATIVIDADE ADMINISTRATIVAS
}

\author{
Rogério Luiz Nery da Silva ${ }^{1}$ \\ Darléa Carine Palma Mattiello ${ }^{2}$
}

\begin{abstract}
Resumo: O tema deste estudo é prestação educacional, com recorte central na discricionariedade administrativa aplicada ao ciclo de políticas públicas. O problema de pesquisa: dosagem do empoderamento decisório de gestores para concretização dos direitos fundamentais. O método de trabalho é hipotético-dedutivo, com pesquisa qualitativa bibliográfica e normativa. Estrutura-se em três partes: pesquisa da relação entre as políticas públicas e a efetivação de direitos; delineamento do direito à educação como direito social; investigação dos contornos da discricionariedade administrativa e seus limites. Conclusão: pela necessidade de equilíbrio entre a discricionariedade e a vinculação na efetivação do direito à educação.
\end{abstract}

Palavras-chave: direitos fundamentais; direitos sociais; direito à educação; políticas públicas; discricionariedade administrativa.

\section{PUBLIC POLICIES AND EDUCATION: THE BALANCING BETWEEN POLITICAL DISCRIMINATION AND ADMINISTRATIVE BINDING}

\begin{abstract}
The issue of this study is educational provision, with a central look at the political discretion applied to the public policy cycle. The research problem: decision-making strength of empowerment to politicians and public agents to realize fundamental rights. The method of work is hypothetical-deductive, with qualitative bibliographical and normative research. Three parts structure: relation between public policies and realization of rights; the right to education as a social right; the contours of political discretion and its limits. Conclusion: the need of a balance between discretion and legal linkage in the decision making for realization of the right to education.
\end{abstract}

Keywords: fundamental righs; social rights; right to education; public policies; political discretion.

\footnotetext{
${ }^{1}$ Pós-doutor pela Université de Paris X (França) e New York Fordham University School of Law (USA). Professor Titular da Cadeira de Políticas Públicas de Direitos Sociais no Curso de Mestrado da UNOESC. Membro Imortal da Academia Brasileira de Ciências Econômicas, Políticas e Sociais (ANE - 1944 - Cátedra n. 196 - Candido Rondon). Endereço postal: Av. Nereu Ramos, Av. Nereu Ramos, 3777-E, Bairro Seminário, CEP 89813-000, Chapecó/SC, Brasil. Endereço eletrônico: dr.rogerionery@gmail.com.

${ }^{2}$ Mestre em Direito pela UNOESC com sanduíche em Direito Comparado na Università degli Studi di Foggia (Itália). Professora na Graduação e Pós-Graduação em Direito da UNOESC. Revisora de Periódicos Jurídicos. Endereço postal: Av. Nereu Ramos, Av. Nereu Ramos, 3777-E, Bairro Seminário, CEP 89813-000, Chapecó/SC, Brasil. Endereço eletrônico: darlea.palma@ unoesc.edu.br.
} 


\section{INTRODUÇÃO}

Os direitos fundamentais reclamam efetivação para viabilizar o pleno desenvolvimento dos povos. As constituições nacionais, em quase a totalidade, albergam previsões voltadas acesso ao ensino e à formação pelas pessoas, como opção ao desenvolvimento, tanto do Estado como das possibilidades de autodeterminação no âmbito de suas vidas individuais, familiares e coletivas.

As características de fundamentalidade costumam se projetar nas constituições com extensas previsões sobre os direitos à vida, à liberdade, à dignidade humana e à igualdade, observados os contextos de espaço e tempo, com, é claro, reconhecidas exceções. Por certo, o entendimento geral reconhece esses direitos, além de outros, como necessários a garantir a completude do ser humano em termos de realização pessoal. É senso comum que a ausência de garantia de tais direitos nega os contornos mínimos da vida livre e de plenas realizações, paralisa o espaço empreendedor e sufoca a criatividade do ser humano, negando-lhe vida própria e a perfeita integração entre povo, estado e governo.

No Brasil, figuram direitos fundamentais individuais (civis e políticos), coletivos (econômico, sociais e culturais) e difusos (os mais diversos), previstos expressa ou implicitamente, com perfis estruturais e funcionais de fundamentalidade, reclamando efetividade máxima, alguns - inarredáveis - de forma incondicionada; outros - menos sensíveis - dentro das possibilidades fáticas razoáveis, segundo a noção de mínimo existencial. O direito social à educação, por lógica, constitui-se pilar do Estado Democrático de Direito e se faz reconhecer como direito inafastável, pertinente ao patrimônio jurídico de cada cidadão e, portanto, exigível de modo permanente, indisponível, indeclinável e irrenunciável.

A educação é fundamental para o desenvolvimento das pessoas, seja qual for o arcabouço legislativo em que se encontre prevista e/ou o conteúdo jurídico ao qual se vincula o seu exercício. Tendo sido discriminada, portanto, como direito fundamental no Brasil, não pode ter sua prestação mitigada, sob pena de ofender, até mesmo, a própria dignidade das pessoas.

A educação deve ter sua prestação assegurada tanto sob o aspecto do acesso às vagas no ensino público, como em termos de condições adequadas de permanência na rotina do sistema educação, no ceio das instituições escolares, como veículo do conhecimento, a garantir opções de escolha na vida de cada um, livre de direcionamentos por terceiros, tornando-o apto à

Rev. de Direito Sociais e Políticas Públicas | e-ISSN: 2525-9881| Maranhão | v. 3 | n. 2 | p. 105 - 121 | Jul/Dez. 2017. 
inserção, permanência e respeito no convívio social - conferindo-lhes, portanto, o necessário empoderamento.

As opções de escolha e de melhoria de vida decorrem da tutela e acesso aos direitos sociais, quando prestados e exercidos. D'outra sorte, as dificuldades são diversas e perenes, impondo-se, permanentemente, a adoção de políticas públicas de concretização desses direitos.

As prestações devem ser asseguradas a todos os que delas efetivamente necessitam. Portanto, ao se cogitar atendê-los, destaca-se o direito à educação na realização dos direitos fundamentais. As políticas públicas, como processos de escolha, dependem, sobremaneira, de decisões dos gestores envolvidos no ciclo de políticas. Para a tomada de decisões, deve-se considerar o alcance legítimo ou excessivo da discricionariedade do administrador, já que, tradicionalmente, o processo decisório tem-se subordinado à rotina das autoridades públicas e corrido a cavaleiro da opinião pública.

Nesse contexto, a discricionariedade administrativa encontra-se intimamente ligada às decisões sobre prestação dos direitos sociais assim como à falha na oferta desses serviços, decorrentes de políticas públicas adequadas ou equivocadas, o que impõe conhecer a estreita relação entre a discricionariedade e as políticas administrativas clássicas.

A presente pesquisa estudará o grau de dependência da prática administrativa em relação à discricionariedade e se essa se constitui em instrumento não apenas hábil, mas indispensável à prestação de serviços públicos com eficiência, neles considerada a educação.

Justifica-se a relevância do estudo pela atenção conferida ao tema na Constituição, a qual prevê "educação básica para todos”, com igualdade de condições, sem maiores distinções, sendo a denegação ofensa ao princípio da dignidade da pessoa humana.

Para a resolução do problema de pesquisa, o trabalho adota o método hipotéticodedutivo, a partir de fontes bibliográficas e do texto normativo, analisando, a um, a relação existente entre as políticas públicas, notadamente as legislativas; a dois, o direito à educação e sua recepção como direito social; a três, os contornos do instituto da discricionariedade administrativa, a fim de clarificar eventual relação com a concretização ou obstaculização dos direitos sociais. 


\section{POLÍticas PÚBLICAS E A EFETIVAÇÃO DE DIREITOS}

Ao adotar postura interventiva, o Estado passa a assumir diversas responsabilidades de atendimento às carências por meio de prestações positivas, a fim de se alcançar melhores condições de vida pela população, associada à aplicação efetiva das normas positivas cogentes. No desempenho desse múnus, de caráter predominantemente vinculativo, portanto, subordinado às determinações legais e constitucionais e, segundo alguns entendimentos, sujeito à vedação de retrocesso.

No atual estágio de evolução do estado como "ator social", as prestações decorrem da busca pela maior e mais eficiente prestação de serviços públicos diretos e indiretos, conforme a deliberação de implantação das políticas públicas específicas.

Bucci (1997, p. 90) afirma, nesse sentido, que o Estado social caracteriza-se por um "agir dos governos sob a forma de políticas públicas", o que abrange um conceito mais amplo que o de serviço público, por incorporar também as funções de coordenação e de físcalização dos agentes públicos e privados.

Pode ser considerada fundamentação para esse "agir" a expressão adquirida por determinadas esferas de direitos no Estado social, ou seja, a própria existência dos direitos sociais afirma-se como fundamento mediato das políticas públicas e justifica o seu aparecimento.

Uma vez que compete ao Estado realizar as prestações que lhe são atribuídas legalmente ${ }^{3}$, os entes públicos devem fazê-lo de forma plena, cumprindo as determinações constitucionais e correspondendo aos anseios da população. Até porque a função estatal de coordenar as ações para a realização de direitos dos cidadãos legitima-se pelo convencimento da sociedade quanto à necessidade de realização desses direitos sociais (BUCCI, 1997, p. 90), o que inclui a prestação dos serviços públicos e a efetivação de direitos como saúde, habitação, previdência, educação, entre tantos outros.

Assim, é extremamente direta a relação existente entre políticas públicas e a realização de direitos fundamentais, especialmente dos direitos sociais, em virtude da demanda de

\footnotetext{
${ }^{3}$ Pelo conceito de "lei" lato sensu abrange toda e qualquer espécie normativa hábil a autorizar o agir do Estado, como Administração Pública. Para Juarez Freitas (2009, p. 70) a "legalidade temperada" abrange o sentido de que a Administração Pública deve pautar-se no direito como "uma totalidade aberta, maior que o conjunto de regras legais", considerando que "o conteúdo jurídico, por força da natureza valorativa, transcende o mera e esparsamente positivado".
}

Rev. de Direito Sociais e Políticas Públicas| e-ISSN: 2525-9881| Maranhão | v. 3 | n. 2 | p. 105 - 121 | Jul/Dez. 2017. 
prestações positivas por parte do Estado a serem veiculadas e efetivamente implementadas por meio das políticas públicas.

As prestações positivas conduzem ao sentido de que se imponha um agir do Estado para garantia dos direitos sociais, porquanto a efetivação de direitos não pode dar-se, apenas, por intermédio de normas legais proibitivas de condutas lesivas e passíveis de infligir sanções.

Arzabe (2001, p.32) considera necessária a normatividade, representada pela existência de leis, regulamentos e medidas públicas de promoção e fortalecimento dos direitos sociais. Os direitos sociais somente são realizáveis por meio das políticas públicas, que fixam as diretrizes e formas para a ação do Poder Público e da sociedade.

O Estado necessita de ações coordenadas e bem estruturadas, específicas para a resolução de determinada celeuma ou para atingir situações peculiares. Além da previsão teórica de prestações positivas, assim, impõem-se articulações entre as esferas de atuação estatal para que os objetivos sejam alcançados.

Segundo Procopiuck (2013, p. 14), a Administração Pública se coloca como dispositivo executivo a serviço de todo o Estado, que se desagrega em um nível institucional e em um nível operativo. Ou seja, o Estado age como uma extensão da organização política que tem atuação condicionada pelo seu próprio arcabouço normativo geral.

Por isso, se o perfil típico do Estado se define pela composição articulada entre os Poderes Legislativo, Executivo e Judiciário, dificilmente, lograr-se-á êxito na efetivação dos direitos fundamentais sociais sem a escorreita utilização de mecanismos como as políticas públicas.

Para Souza (2007, p. 68), não existe uma única, nem melhor, definição sobre o que seja política pública. Pode-se afirmar, assim, que o termo pode assumir abordagens diferentes conforme venha a implicar em decisões ou em determinadas etapas, que vão desde a tomada inicial das deliberações até a implementação da política.

Trata-se, portanto, segundo Souza (2007, p. 83), do campo do conhecimento que busca integrar alguns elementos, como a própria política pública (policy), a política (politics), a sociedade política (polity) e as instituições que regem as decisões, os desenhos e as implementações das políticas públicas, focalizando seu processo e seus resultados.

Certo é que as políticas públicas constituem-se de atividades cíclicas e interligadas; uma fase depende e influencia na outra, envolvendo a ação de diversos atores em busca do bem estar coletivo. Nesse ponto reside, provavelmente, o índice para o sucesso das políticas: a existência

Rev. de Direito Sociais e Políticas Públicas| e-ISSN: 2525-9881| Maranhão | v. 3 | n. 2 | p. 105 - 121 | Jul/Dez. 2017. 
de fases interdependentes entre si, dependendo de diversos atores e ciclos exitosos para que se obtenha a efetivação dos direitos almejada.

Fator igualmente determinante para o sucesso das políticas é o sistema político federativo em que se inserem. Além da estruturação estatal em Poderes autônomos, no caso do Brasil, tem-se uma configuração que confere diferentes autonomias aos entes federativos, quais sejam: União, Estados-membros, Distrito Federal e Municípios.

Assim, complicações podem ser causadas, por exemplo, para a prática de políticas nacionais que dependam da implementação de ações locais ou regionais para o seu êxito. No que tange aos direitos fundamentais sociais, principalmente, verifica-se a necessidade de ações interligadas entre os entes federativos e suas esferas de atuação, residindo, nesse ponto, fator categórico para o (in)sucesso das políticas.

Baptista e Rezende (2011, p. 161) esclarecem que, no caso brasileiro, a configuração do sistema político federativo traz algumas complicações a mais em análise desta natureza. Seria inviável, assim, falar de implementação de políticas nacionais quando estados e municípios exercem ou são chamados a exercer sua autonomia local.

Por essas questões, devem ser possibilitadas análises que reflitam o debate político em questão e que não são simples reproduções de modelos políticos nacionais e universais, importando saber em que contextos se inserem as políticas, suas especificidades e o arranjo que se constitui em cada caso.

Até porque a ideia de um ciclo da política com as fases delimitadas pode funcionar muito bem para o controle e a definição de políticas que subsidiem a tomada das decisões, mas não tão bem para a verificação do êxito dos processos que foram desencadeados.

Percebe-se assim que, como instrumentos de ação dos governos, as políticas públicas devem acompanhar as necessidades sociais para efetivação dos direitos insculpidos normativamente, com a verificação das potencialidades, necessidades e atribuições políticas federativas locais.

Nos dizeres de Bobbio (2004, p. 203), “direitos do homem, democracia e paz são três momentos necessários do mesmo movimento histórico: sem direitos do homem reconhecidos e efetivamente protegidos não existe democracia”. As políticas públicas, assim, por se constituírem utensílios de efetivação dos direitos sociais, tratam-se também de verdadeiros instrumentos de democracia.

Rev. de Direito Sociais e Políticas Públicas | e-ISSN: 2525-9881| Maranhão | v. 3 | n. 2 | p. 105 - 121 | Jul/Dez. 2017. 
No mesmo sentido, Atria (2005, p. 19) considera razoável pensar que as características que o direito subjetivo adota são um reflexo importante acerca dos direitos morais que o direito pretende proteger. É a isso que se deve atentar: à possibilidade de o direito acompanhar os fatos sociais, para concretizar, por meio das políticas públicas, o que se faz necessário, de fato, para o pleno desenvolvimento dos cidadãos, destinatários da previsão constitucional dos direitos sociais.

\section{O DIREITO À EDUCAÇÃO E SUAS VERTENTES}

Dentre os direitos sociais a serem prestados pelo Estado, merece destaque o direito à educação. Não há como se falar em um Estado evoluído, promotor de igualdade e de bem estar social sem se cogitar avanços no sistema educacional e a efetiva prestação desse direito.

Sobre o direito à educação configurar-se em um direito subjetivo, invocam-se as palavras de Garcia (2004), para quem, tanto o direito objetivo como o subjetivo possuem um epicentro comum: a pessoa, natural ou jurídica, que é a titular em potencial das relações jurídicas que se desenvolvem no organismo social. Nessa linha de pensamento, enquanto o direito objetivo ocupa uma vertente externa à pessoa, mas a ela direcionada, o direito subjetivo se realiza na própria pessoa, razão de situar o direito à educação como direito subjetivo.

Não à toa, a educação é um dos direitos fundamentais determinantes para o exercício de uma vida digna. Deve ser prestada pelo Estado de forma efetiva e apta a propiciar o efetivo exercício da dignidade, assim considerada como sendo um princípio basilar que não se coaduna com a possibilidade de ponderação.

Pode-se afirmar, por consequência, que a racionalidade e o conhecimento propiciados pela educação são cruciais para o exercício da dignidade da pessoa humana, por ser o homem considerado como um fim em si mesmo e em função da sua autonomia enquanto ser racional (KANT, 2004). Fornecendo, a educação, autonomia, reforçar-se-ia a lei universal que refuta a utilização do homem como meio para outro fim que não seja ele mesmo.

O direito à educação e o princípio a dignidade da pessoa humana tanto se relacionam que várias declarações de direitos ressaltam a relevância da educação para uma vida digna, assim como a inserem no rol dos direitos fundamentais ${ }^{4}$.

\footnotetext{
${ }^{4}$ No sentido de esclarecer que a dignidade da pessoa humana é ponto central ("núcleo duro") dos direitos fundamentais para vários povos, consoante explicitado nas várias declarações de direitos, esclarecem Baez e Mozetic (2013) que devem ser examinados os valores propostos com uma visão intercultural, sem o condão de
} 
No mesmo sentido, vinculando-se a educação com o princípio da dignidade da pessoa humana, Häberle (2009, p. 81) afirma que a exata compreensão do que vem a ser o estado de direito depende da existência de um compromisso de sua Constituição com a dignidade humana. A educação, nesse entendimento, contribui ao figurar como norma fundamental do Estado, apta a fundamentar a sociedade já constituída ou por ser constituída.

A fundamentalidade é inerente ao direito à educação. Trata-se de direito incluído comumente como dependente de prestações estatais positivas, assim como os demais direitos sociais.

Na concepção de Alexy (2015, p. 433-434), os direitos à assistência social, ao trabalho, à moradia e à educação constituem o que é denominado "direito a prestações", ou seja, os direitos a uma ação positiva do Estado, que pertencem a um status positivo, em sentido estrito. Em contraponto, viriam os direitos de defesa do cidadão contra o Estado, constituindo-se direitos a ações negativas do Estado.

Já para Sarlet (2012, p. 260), os direitos fundamentais, em razão de sua multifuncionalidade, podem ser classificados basicamente em dois grandes grupos, nomeadamente os direitos de defesa e os direitos a prestações. Incluem no primeiro grupo os direitos de liberdade, igualdade, as garantias, bem como parte dos direitos sociais (no caso, as liberdades sociais) e políticos; o segundo grupo, por sua vez, integra-se pelos direitos a prestações em sentido amplo, tais como os direitos a proteções em sentido estrito, representados pelos direitos sociais de natureza prestacional, dentre os quais figura o direito à educação.

No mesmo sentido, quanto à exigibilidade dos direitos sociais, seu reconhecimento constitucional e a relação com prestações positivas, Abramovich e Courtis (2009, pp. 4-6) sustentam que, por se tratar de direitos que estabelecem obrigações positivas, "o seu cumprimento depende da provisão de fundos públicos e, por esta razão, o Poder Judiciário não poderia impor ao Estado o cumprimento de uma conduta de dar ou fazer" ${ }^{\prime \prime}$, veiculando a prestação dos direitos sociais a prestações positivas, muitas vezes custosas ao Estado.

Salientam os mesmos autores, porém, que os direitos sociais - referindo-se, especificamente, a diversas espécies de direitos como o direito à saúde, à moradia, à educação e à seguridade social - não se esgotam em prestações positivas, porque "como no caso dos

\footnotetext{
atribuir supremacia de uma nação sobre a(s) outra(s), haja vista a existência de culturas antagônicas que impossibilitaram, até a atualidade, o entendimento global sobre uma categoria universal de direitos fundamentais. ${ }^{5}$ Abramovich e Courtis (2009, pp. 4-6): "su cumplimiento depende de la disposición de fondos públicos, y que por ello el Poder Judicial no podría imponer al Estado el cumplimiento de conductas de dar o hacer"
}

Rev. de Direito Sociais e Políticas Públicas | e-ISSN: 2525-9881| Maranhão | v. 3 | n. 2 | p. 105 - 121 | Jul/Dez. 2017. 
direitos civis, quando os proprietários já aderiram à propriedade que é objeto desses direitos, o Estado tem a obrigação de se abster de conduzir uma conduta que a afeta"6.

Bucci (1997, p. 90) assevera que os direitos sociais, dentre o rol de direitos fundamentais do homem, efetivam-se por meio de prestações positivas do Estado. Enquanto os direitos individuais, ditos direitos fundamentais de primeira geração, consistem em liberdades, os direitos sociais, ditos de segunda geração, consistem em poderes. Assim, somente poderiam ser realizados se forem impostas, a outros, obrigações positivas, incluídos aqui os órgãos públicos.

É intensa a discussão sobre os direitos fundamentais sociais serem considerados unicamente prestacionais. De tal discussão, não pode se afastar o direito à educação, que é fundamental e prestacional por natureza.

Há divergência, ainda, sobre o fato de a educação consistir, ou não, em um direito fundamental (CESAR; VIANA, 2009). A doutrina mais atual reconhece os direitos fundamentais como prerrogativas que o indivíduo tem em face do Estado, abrangendo os direitos individuais, sociais (como o educacional) e políticos.

Entretanto, nada obstantes tais discussões, sob todos os pontos de vista, a educação, longe de ser um enfeite ou o resultado da vaidade das pessoas, possibilita o desenvolvimento ideal da personalidade humana, constituindo-se condição indispensável para a concretização da própria cidadania. Segundo Garcia (2004), com ela, o indivíduo compreende o alcance de suas liberdades, a forma de exercício de seus direitos e a importância de seus deveres, permitindo a sua integração em uma democracia efetivamente participativa.

No mesmo sentido, manifesta-se Baruffi (2011, p. 149), ao afirmar que a educação é um direito que não pode ser "mera retórica ou simples folha de papel", pois possui força transformadora. Verificam-se, assim, na educação fundamentos para as políticas públicas e a resposta que o constituinte deu à sociedade ao inseri-la como direito fundamental social.

Assim, em essência, educação é o passaporte para a cidadania. Além disso, segundo Garcia (2004), é um dos pressupostos para a evolução de qualquer Estado de Direito, pois a qualificação e a capacidade crítica dos indivíduos mostram-se imprescindíveis ao alcance desse objetivo.

\footnotetext{
${ }^{6}$ Ibidem (2009, p. 5) "al igual que en el caso de los derechos civiles, cuando los titulares hayan ya accedido al bien que constituye el objeto de esos derechos, el Estado tiene la obligación de abstenerse de realizar conductas que lo afecten".
}

Rev. de Direito Sociais e Políticas Públicas| e-ISSN: 2525-9881| Maranhão | v. 3 | n. 2 | p. 105 - 121 | Jul/Dez. 2017. 
Significa dizer que, ainda que concebido como um direito social, ocupando uma segunda geração ou dimensão, a efetividade do direito à educação é imprescindível à própria salvaguarda do direito à livre determinação.

A educação, assim, embora considerada um direito social, é imprescindível à salvaguarda de um direito que, sob um prisma lógico-evolutivo, o antecede na formação do Estado de Direito: a liberdade (GARCIA, 2004), demonstrando que direitos de primeira e de segunda dimensões, sejam definidos como negativos ou positivos, de defesa ou prestacionais, podem - e devem - conviver de forma afinada, indissociável e com nexo de complementaridade.

\section{A DISCRICIONARIEDADE ADMINISTRATIVA}

Ao longo do tempo, processos que objetivam efetivar o direito à educação ganham proporção no Estado brasileiro, definindo modos de ação, envolvendo os mais diversos atores e dependendo das diferentes esferas governamentais. Incluem-se, aqui, determinações que podem se coadunar com a descrição de Sarlet (2012, p. 266), no sentido de estabelecerem programas, finalidades e tarefas mais ou menos concretas a serem implementadas pelos órgãos estatais.

Esses atos correspondem a uma exigência do Estado Social de Direito, ainda mais quando se trata de efetivação de direitos sociais. No que tange ao direito à educação, especificamente, o papel dos atores das políticas, envolvidos nos processos decisórios, adquire especial relevância, porquanto se trata de direito que demanda prestações positivas por parte do Estado para efetivação.

Nesse sentido, segundo Baruffi (2011, p. 153), para que seja efetivada como um direito fundamental social, a educação necessita não apenas de oferta pelos poderes constituídos, mas, também, de ações necessárias para que o direito atenda às suas finalidades previstas constitucionalmente.

Os agentes políticos ${ }^{7}$ possuem participação decisiva e fundamental, porquanto gestores dos recursos hábeis a viabilizar as atividades previstas. Desde o planejamento à execução das políticas públicas, por meio de planos de gestão governamental, passando pelos programas gerais e setoriais, até alcançar os projetos executivos e as ações de campo a serem desenvolvidas, tudo tem um grau de dependência maior ou menor da atividade governamental.

\footnotetext{
${ }^{7}$ Ainda remanesce certa contradição doutrinária sobre quais as classes incluídas como "agentes políticos".
} 
Assim, pouco se pode encaminhar sem que se identifique uma sensível dependência, ao menos, da participação do Estado, já que este detém o poder decisório acerca da destinação dos recursos públicos. Nessa atividade, o Estado se faz representado pela Administração Pública, que, em última análise, se traduz pela ação de suas pessoas (entes ou entidades), agentes, órgãos, todos embalados pela previsão de variados graus de espectro decisório.

Bucci (1997, p. 96) esclarece que há em comum entre as políticas a existência de um processo político de escolha das prioridades, não obstantes suas diferentes acepções, mas as agrupando em um mesmo conceito jurídico, ou seja, o governo elege as prioridades tanto em termos objetivos como no que tange aos procedimentos a serem adotados.

Tudo isso é realizado conforme a mensuração da conveniência da prática de cada ato administrativo e da exata oportunidade com que isso deva se operar - é o que se designa, convencionalmente, de discricionariedade administrativa.

Segundo Silva (2008, p. 590), ao contrário do que ocorre com a realização e a proteção dos direitos individuais, a realização dos direitos sociais, por depender de gastos públicos, depende de decisões que extrapolam o simples raciocínio jurídico-formal, mas, sobretudo, de vontade política, expressada por meio de escolhas e decisões políticas e técnicas, que dependem, por vezes, excessivamente da discricionariedade de agentes políticos e de agentes administrativos a eles subordinados.

Em um panorama de escassez de recursos, no qual não há verbas suficientes para resolver nem mesmo os principais problemas de saúde, educação e moradia dos indivíduos (realidade que assola muitos países), é necessário muito equilíbrio para a tomada de decisão sobre como e onde os recursos públicos serão alocados. Nesses termos, o Estado confere aos agentes públicos maior potencial decisório e avaliador das balizas norteadoras da ação discricionária, o que pode trazer pontos positivos, mas, também muito negativos.

É fundamental conhecer o papel de tais agentes no contexto da implantação de políticas públicas, a partir da análise do texto constitucional e da legislação correlata aplicável, por meio da regulamentação pelo Poder Executivos, no âmbito dos entes federados, tomando-se por referência a necessidade de identificação dos fatores determinantes da atuação dos agentes públicos (políticos, administrativos e colaboradores), cada um, a seu turno, exercendo maior ou menor nível decisório ou de assessoramento, direto e indireto, como propulsores de uma imensa engrenagem que é a atividade administrativa.

Rev. de Direito Sociais e Políticas Públicas| e-ISSN: 2525-9881| Maranhão | v. 3 | n. 2 | p. 105 - 121 | Jul/Dez. 2017. 
Por conseguinte, remete-se excessivamente o desenho das políticas públicas aos administradores estatais (ou governantes, por assim dizer). Nesse contexto, situam-se os indivíduos, grupos ou organizações que desempenham algum papel do processo de políticas públicas, os quais são denominados atores.

Os atores relevantes em um processo de política pública são aqueles capazes de influenciar, direta ou indiretamente, o conteúdo e os resultados da política pública; em meio a esses, figuram os atores governamentais, patamar em que se situam os agentes públicos.

A Administração Pública desempenha suas funções (governo) por intermédio da atuação de agentes públicos. A expressão "agente público", assim, seria um gênero que abrange as pessoas físicas que prestam um serviço ao Estado, sob as mais diversas formas de relação (estatutária ou celetista, por exemplo).

Definindo-se agentes públicos como sendo um gênero, pode-se encontrar, como espécie, a categoria dos agentes políticos, em paralelo com os servidores públicos lato sensu (estatutários, empregados públicos e servidores temporários) e os particulares em colaboração com o poder público, entre outros, dependendo da classificação doutrinária a ser adotada.

Os agentes políticos ${ }^{8}$ são aqueles que possuem funções de direção e de orientação, de exercício geralmente transitório. Sua investidura dá-se, geralmente, por meio de eleição, investidos de um mandato, caracterizando a transitoriedade do exercício das funções. Esses agentes exercem funções políticas como representantes da vontade da coletividade, desenvolvendo atividades de definição das diretrizes e dos planos governamentais ${ }^{9}$.

Embora sejam atores com importante papel nos processos decisórios que permeiam quaisquer políticas públicas, hoje, se questiona a demasiada submissão dos processos decisórios em suas mãos, propondo-se a integração ao processo de diversos outros tipos de atores, baseada na queda de representatividade, principalmente da classe legislativa. Esses agentes exercem funções de Estado, no sentido de avaliar e ponderar as necessidades da coletividade, como e

\footnotetext{
${ }^{8}$ Ainda remanesce certa contradição doutrinária sobre quais as classes incluídas como "agentes políticos"

${ }^{9}$ Importante frisar que parte da doutrina administrativa enquadra na espécie de agente político todos aqueles que possuem atribuições decorrentes diretamente da própria Constituição, o que é corroborado pela jurisprudência. É o entendimento do Supremo Tribunal Federal (STF), transcrito no Informativo 259, referindo o RE 228.977, de relatoria do Min. Néri da Silveira (BRASIL, 2002). Assim, além dos agentes que exercem função eminentemente política, seriam agentes políticos, ainda, os membros da magistratura, do Ministério Público, dos Tribunais de Contas, os representantes diplomáticos e outras autoridades que atuem com independência funcional no exercício de atribuições governamentais, ainda que estranhas ao quadro do funcionalismo estatutário. Precipuamente, seriam agentes políticos, segundo essa ampla classificação, aqueles cuja remuneração se dá pelo regime de subsídio. Para os fins do presente estudo, porém, será adotada a definição mais restritiva, considerando-se agentes políticos aqueles caracterizados por exercerem funções políticas como representantes da vontade da coletividade.
}

Rev. de Direito Sociais e Políticas Públicas| e-ISSN: 2525-9881| Maranhão | v. 3 | n. 2 | p. 105 - 121 | Jul/Dez. 2017. 
quando serão prestados os direitos sociais, consoante as disponibilidades de instrumentos estatais, valendo-se de conveniência e oportunidade, mas que não podem nem devem se desvincular, sob hipótese alguma, da estrita legalidade, em cada um de seus atos.

Para Sarlet (2008, p. 29), as prestações estatais básicas destinam-se à garantia de uma vida digna para as pessoas, constituindo-se parâmetro necessário para a justiciabilidade dos direitos sociais prestacionais. Sustenta-se, assim, que direitos subjetivos definitivos prevalecem até mesmo em face de outros princípios constitucionais, como, por exemplo, o da reserva do possível.

Daí a importância do escorreito exercício da discricionariedade pelos agentes com poderes decisórios, porquanto de suas escolhas poderá advir maior ou menor grau de efetividade dos direitos sociais. Em sendo, tais direitos, previstos como fundamentais pelo Estado brasileiro, sua não observância acarretará um inadimplemento por parte dos Poderes estatais e uma significativa perda aos cidadãos, que não terão concretizados os direitos necessários à vida digna.

\section{CONCLUSÃO}

Em atendimento às determinações constitucionais e infraconstitucionais, o Estado brasileiro tem o dever de desempenhar uma série de obrigações sociais para com a população. Considerando-se o agir estatal como um complexo de atividades administrativas, jurisdicionais e legislativas, as políticas públicas são veiculadas nas mais diversas esferas por intermédio do Poder Público.

São inerentes à atuação estatal prestações com caráter vinculativo, subordinadas a determinações legais e constitucionais. No atual Estado social, principalmente, são realizadas muitas prestações positivas, com o objetivo de efetivar os direitos constitucionais fundamentais.

Embora se classifiquem os direitos fundamentais a partir de dimensões, em plataforma segundo a qual os de primeira dimensão são tidos por negativos e os de segunda dimensão, por positivos, é necessário que esses direitos se complementem uns aos outros, com vistas a uma verdadeira concreção.

O direito à educação, por exemplo, embora vislumbrado tradicionalmente como passível de efetivação com prestações positivas, é essencial para a consagração do direito à liberdade, o qual se configuraria com a atuação negativa por parte do Estado, ou seja, com a sua abstenção.

Rev. de Direito Sociais e Políticas Públicas| e-ISSN: 2525-9881| Maranhão | v. 3 | n. 2 | p. 105 - 121 | Jul/Dez. 2017. 
Da mesma forma, o direito à educação relaciona-se intimamente com a dignidade da pessoa humana, que é um dos fundamentos do Estado Democrático de Direito. Sob esse ponto de vista, embora seja considerado um direito social, veiculado por meio de um agir positivo do Estado, a efetividade do direito à educação propicia o exercício das liberdades e da dignidade pela pessoa humana, em todos os seus aspectos.

Por tudo isso, é estreita a relação existente entre políticas públicas e a realização do direito fundamental à educação, em virtude da demanda de prestações positivas por parte do Estado a serem veiculadas e efetivamente implementadas por meio de políticas, sejam elas legislativas, administrativas ou, ainda, por meio da jurisdição.

Além de se caracterizarem como instrumentos de ação, envolvendo processos decisórios, ciclos e diversos atores, as políticas públicas possuem como característica acompanhar as necessidades sociais, sendo essenciais para a efetivação do direito à educação. Percebe-se, por exemplo, uma série de medidas adotadas, de forma interligada e complementar, entre União, Estados e Municípios para que se alcancem melhores estatísticas de acesso e permanência nas instituições escolares.

A educação, porém, vai além desses fatores de avaliação; deve constituir-se em verdadeiro e eficaz meio de conhecimento, propiciando opções de escolha para uma vida melhor por todos os cidadãos. Trata-se de direito fundamental, subjetivo, que se reflete em verdadeiro alicerce para o crescimento pessoal, profissional e social, ou seja, um legítimo degrau de acesso à cidadania.

Significa dizer que o direito à educação, quando exercido plenamente, é imprescindível à própria preservação do direito às liberdades, em todos os seus aspectos - embora tenha sido concebido como um direito social, ocupando uma segunda geração ou dimensão.

O Estado possui relevante papel na efetivação desse direito. Para tanto, no cumprimento dos ônus que lhe são inerentes, costuma promover um "sem-fim" de políticas nas mais diversas esferas. E as políticas públicas, como se sabe, demandam de todo um processo decisório e cíclico, o que culmina por relacioná-las à atividade dos gestores.

Analisando-se o papel dos agentes públicos nesse processo, percebe-se que possuem posição definidora e basilar, vindo a agir, muitas vezes, pautados em atos discricionários. Afinal, nem sempre é possível agir concretizando direitos por meio de medidas adequadas sem que sejam demandadas escolhas que não sejam atribuídas à Administração Pública de forma vinculada.

Rev. de Direito Sociais e Políticas Públicas| e-ISSN: 2525-9881| Maranhão | v. 3 | n. 2 | p. 105 - 121 | Jul/Dez. 2017. 
Muitas vezes, é pela conveniência e pela oportunidade que os atores das políticas públicas agem, especificamente quando se trata de autoridades com poderes de gestão pública. Assim, a discricionariedade administrativa assume papel determinante na realização das políticas idealizadas para a concretização dos direitos sociais, por ser o que definirá prioridades e procedimentos.

Quando se trata do direito à educação, é recorrente a proposição de políticas de inclusão, de acesso e permanência nas instituições escolares, de formação de professores, dentre outras. Entretanto, não é somente nisso que repousa a atuação dos gestores, já que a discricionariedade afeta medidas aptas a garantir a educação não apenas em um aspecto formal, mas, sim, substancial, de forma que se forneça às pessoas conhecimento e opções de escolha.

A educação deve tornar seus destinatários aptos à inserção, à permanência e ao respeito no convívio social, a ponto de lhes conferir empoderamento pessoal. Dessa forma, as políticas públicas promovidas com esse fim não podem dispensar critérios hígidos de escolha, desde a concepção até a execução das medidas estatais, passando pela adequação da agenda e pelos atores envolvidos.

Revela-se, nesse mote, o marco determinante da exata delimitação da abrangência da janela aceitável de discricionariedade administrativa no universo de vinculação que a segurança administrativa exige, no processo não apenas decisório, mas executório das políticas públicas, principalmente as que exijam a aplicação elevada de recursos financeiros, como se dá com as voltadas aos direitos sociais, ex vi, especificamente, do direito à educação, recentemente, objeto de alteração pela nova Lei do Ensino Médio, cujos contornos, certamente, darão azo a incansáveis discussões sobre seus acertos e erros e já colecionam diversas imputações de inconstitucionalidade.

\section{REFERÊNCIAS}

ABRAMOVICH, Victor; COURTIS, Christian. Apuntes sobre la exigibilidad judicial de los derechos sociales. In: Courtis, Christian; Santamaría, Ramiro Ávila. La protección judicial de los derechos sociales. $1^{\mathrm{a}}$ ed. V\&M Gráficas. Quito, Ecuador: 2009. p. 3-29.

ALEXY, Robert. Teoria dos direitos fundamentais. Trad. Virgílio Afonso da Silva. $2^{\mathrm{a}}$ ed., $4^{\mathrm{a}}$ tir. São Paulo: Malheiros, 2015.

ARZABE, Patrícia Helena Massa. Conselhos de Direitos e Formulação de Políticas Públicas. In: Direitos Humanos e Políticas Públicas. São Paulo: Pólis, 2001. P. 32- 43. Disponível em: http://www.bibliotecadigital.abong.org.br/handle/11465/441. Acesso em: 06.ago.2015. 
ATRIA, Fernando. Existem direitos sociais? In: MELLO, Claudio Ari (coord.). Os desafios dos direitos sociais. Revista do Ministério Público do Rio Grande do Sul, n. 56, set/dez 2005. Porto Alegre: Livraria do Advogado, 2005, p. 9-46.

BAEZ, Narciso Leandro Xavier; MOZETIC, Vinicius Almada. A morfologia das teorias universalistas dos Direitos Humanos Fundamentais. In: ALEXY, Robert; BAEZ, Narciso Leandro Xavier; SANDKÜHLER, Hans Jörg; HAHN, Paulo (org.). Níveis de efetivação dos direitos fundamentais e sociais: um diálogo Brasil e Alemanha. Joaçaba: Ed. Unoesc, 2013.

BAPTISTA, Tatiana W. F.; REZENDE, Mônica. A ideia de ciclo na análise de políticas públicas. In MATTOS, R. A.; BAPTISTA, T. W. F. Caminhos para análise das políticas de saúde, 2011. P.138-172. Disponível em: http://www.ims.uerj.br/pesquisa/ccaps/wpcontent/uploads/2011/09/Capitulo-5.pdf. Acesso em: 29.out.2015.

BARUFFI, Helder. A educação como um direito social fundamental: positivação e eficácia. In: Educação e Fronteiras On-Line. Dourados/MS, v.1, n.3, set./dez. 2011, p.146-159.

BOBBIO, Norberto. A Era dos Direitos. Trad. Carlos Nelson Coutinho. Rio de Janeiro: Elsevier, 2004.

BRASIL. Constituição da República Federativa do Brasil de 1988. Disponível em: http://www.planalto.gov.br/ccivil_03/constituicao/constituicao.htm. Acesso em: 06 jan.2016.

BRASIL. Supremo Tribunal Federal. Informativo de jurisprudência n. 259. Pesquisa de Jurisprudência. Brasília, 4 a 8 de março de 2002. Disponível em: http://www.stf.jus.br/arquivo/informativo/documento/informativo259.htm. Acesso em: 10 mar.2014.

BUCCI, Maria Paula Dallari. Políticas públicas e direito administrativo. In: Revista de Informação Legislativa. Brasília, v. 34, n. 133, p. 89-98, jan./mar. 1997. Disponível em: http://www2.senado.leg.br/bdsf/item/id/198. Acesso em: 05.ago.2015.

CESAR, Raquel Coelho Lenz; VIANA, Mateus Gomes. Direito à educação no Brasil: exigibilidade constitucional. In: XV Encontro de Iniciação à Pesquisa, 2009, Fortaleza. Encontro de Iniciação à Pesquisa. Fortaleza: Unifor, 2009. v. 1. pp. 1-6. Disponível em: http://www.egov.ufsc.br/portal/linha_educacao?page=22. Acesso em: 04.mar.2015.

FREITAS, Juarez. O controle dos atos administrativos e os princípios fundamentais. 4. ed. São Paulo: Malheiros, 2009.

GARCIA, Emerson. O Direito à Educação e suas Perspectivas de Efetividade. In: Revista Jurídica Virtual. Vol. 5, n. 57. Fev. 2004. Disponível em:

http://www.planalto.gov.br/ccivil_03/revista/Rev_57/Artigos/Art_Emerson.htm. Acesso em: 03.mar.2015.

HÄBERLE, Peter. A dignidade humana como fundamento da comunidade estatal. In: SARLET, Ingo Wolfgang (Org.). Dimensões da dignidade: ensaios de filosofia do direito e 
direito constitucional. 2. ed, rev. et ampl. Porto Alegre: Livraria do Advogado, 2009, pp. 45103.

KANT, Immanuel. Fundamentação da metafísica dos costumes e outros escritos. Trad. Leopoldo Holzbach. São Paulo: Martin Claret, 2004.

PROCOPIUCK, Mario. Origens e Fundamentos da Administração Pública. In: Procopiuck, Mario. Políticas públicas e fundamentos da administração pública: análise e avaliação, governança e redes de políticas, administração judiciária. São Paulo: Atlas, 2013, pp. 10-15.

SARLET, Ingo Wolfgang. A eficácia dos direitos fundamentais: uma teoria geral dos direitos fundamentais na perspectiva constitucional. Porto Alegre: Livraria do Advogado, 2012.

SARLET, Ingo Wolfgang. Proibição do retrocesso, dignidade da pessoa humana e direitos sociais: manifestação de um constitucionalismo dirigente possível. In: Revista Eletrônica sobre a Reforma do Estado (RERE), Salvador, Instituto Brasileiro de Direito Público, n. 15, setembro/outubro/novembro 2008. Disponível em:

http://www.direitodoestado.com.br/rere.asp. Acesso em: 15 ago.2015.

SILVA, Virgílio Afonso da. O Judiciário e as políticas públicas: entre transformação social e obstáculo à realização dos direitos sociais. In: SOUZA NETO, Cláudio Pereira;

SARMENTO, Daniel. Direitos Sociais: fundamentação, judicialização e direitos sociais em espécies. Rio de Janeiro: Lumen Juris, 2008, pp. 587-599.

SOUZA, Celina. Estado da Arte da Pesquisa em Políticas Públicas. In: Hochman, Gilberto; Arretche, Marta; Marques, Eduardo. Políticas Públicas no Brasil. Rio de Janeiro: Editora FioCruz, 2007, pp. 65-86. 